\title{
Submarine landslide as the source for the October 11, 1918 Mona Passage tsunami: Observations and modeling
}

\author{
A.M. López-Venegas ${ }^{\text {a,* }}$, U.S. ten Brink ${ }^{\text {a }}$, E.L. Geist ${ }^{\text {b }}$ \\ a U.S.G.S. Woods Hole Science Center, 384 Woods Hole Road, Woods Hole, MA 02543, United States \\ ${ }^{\mathrm{b}}$ U.S.G.S. Coastal and Marine Geology, 345 Middlefield Road, Menlo Park, CA 94025, United States
}

\section{A R T I C L E I N F O}

\section{Article history:}

Received 15 January 2008

Received in revised form 12 April 2008

Accepted 7 May 2008

\section{Keywords:}

tsunamis

Mona Passage

October 11, 1918

Puerto Rico

submarine landslide

tsunami modeling

\begin{abstract}
A B S T R A C T
The October 11, $1918 M_{\mathrm{L}} 7.5$ earthquake in the Mona Passage between Hispaniola and Puerto Rico generated a local tsunami that claimed approximately 100 lives along the western coast of Puerto Rico. The area affected by this tsunami is now significantly more populated. Newly acquired high-resolution bathymetry and seismic reflection lines in the Mona Passage show a fresh submarine landslide $15 \mathrm{~km}$ northwest of Rinćon in northwestern Puerto Rico and in the vicinity of the first published earthquake epicenter. The landslide area is approximately $76 \mathrm{~km}^{2}$ and probably displaced a total volume of $10 \mathrm{~km}^{3}$. The landslide's headscarp is at a water depth of $1200 \mathrm{~m}$, with the debris flow extending to a water depth of $4200 \mathrm{~m}$.

Submarine telegraph cables were reported cut by a landslide in this area following the earthquake, further suggesting that the landslide was the result of the October 11, 1918 earthquake. On the other hand, the location of the previously suggested source of the 1918 tsunami, a normal fault along the east wall of Mona Rift, does not show recent seafloor rupture. Using the extended, weakly non-linear hydrodynamic equations implemented in the program COULWAVE, we modeled the tsunami as generated by a landslide with a duration of $325 \mathrm{~s}$ (corresponding to an average speed of $\sim 27 \mathrm{~m} / \mathrm{s}$ ) and with the observed dimensions and location. Calculated marigrams show a leading depression wave followed by a maximum positive amplitude in agreement with the reported polarity, relative amplitudes, and arrival times.

Our results suggest this newly-identified landslide, which was likely triggered by the 1918 earthquake, was the primary cause of the October 11, 1918 tsunami and not the earthquake itself. Results from this study should be useful to help discern poorly constrained tsunami sources in other case studies.
\end{abstract}

Published by Elsevier B.V.

\section{Introduction}

On the morning of Friday, October 11, 1918 at around 10:14 am, Puerto Rico experienced a $M_{\mathrm{L}} 7.5$ (Gutenberg and Richter, 1954), $M_{\mathrm{W}}$ 7.2 (Doser et al., 2005) earthquake originating in the Mona Passage between Puerto Rico and the Dominican Republic. The seismic waves were followed promptly by a tsunami that mostly affected the western coast of Puerto Rico. As a result, more than 100 people lost their lives and many others were displaced by the destruction which at the time exceeded \$4,000,000 (Reid and Taber, 1919). Although this number may sound small, a repeat of such an event today would be catastrophic and damages could be in the tens of millions of dollars (ten Brink et al., 1999), primarily due to the increased population and development along the coasts of Puerto Rico.

\footnotetext{
* Corresponding author.

E-mail addresses: alopez@usgs.gov (A.M. López-Venegas), utenbrink@usgs.gov (U.S. ten Brink), egeist@usgs.gov (E.L. Geist).
}

Previous modeling of the October 11, 1918 tsunami (Mercado and McCann, 1998) assumed an instantaneous fault dislocation as the origin of the tsunami. Although their fault model yielded overall good arrival times, it was unable to reproduce the observed first arrival polarities and overall amplitudes.

We present an alternative mechanism for the tsunami based on the assumption that the earthquake triggered a landslide and the landslide movement generated the tsunami. Historical evidence of telegraph cables broken in the landslide area during the 1918 earthquake corroborate this suggestion. We report here the results from our tsunami modeling and discuss the feasibility of our selected source over previously suggested scenarios. Because this study benefits from historical evidence, quality bathymetry and seismic reflection data, run-up, inundation and arrival time values at selected locations, and realistic tsunami modeling, makes it a good case study for other events where tsunami sources are still unclear or poorly known.

Our suggestion is based on high-resolution bathymetry data acquired aboard NOAA Ship R/V Ronald Brown during June 2004 and multichannel seismic reflection lines acquired aboard the Louisiana 
Universities Marine Consortium Ship R/V Pelican during October 2006 identified a fresh submarine landslide.

\section{Previous suggestion for the origin of the 1918 tsunami}

The island of Puerto Rico and the Virgin Islands comprise one of several microplates within the complexly deformed Northern Caribbean Plate Boundary Zone (Mann and Burke, 1984). The Mona Rift has been identified as an active feature serving as the microplate's western boundary. Extension rate across the predominantly northsouth rift has been estimated to be up to $5 \pm 4 \mathrm{~mm} / \mathrm{yr}$ (Jansma et al., 2000). Although the Mona Rift is considered an active boundary, it does not connect to the Puerto Rico Trench to the north and does not extend farther south to the Muertos Trough, the microplate's southern boundary.

Mercado and McCann (1998) re-interpreted available Mona Passage seismic reflection lines from the early 1970's and identified eight active faults in the Mona Rift. Among those faults, they chose the Mona Canyon fault, a north-south trending normal fault along the eastern wall of the Mona Rift as the preferred source for the generation of the tsunami (black dashed line in Fig. 1).

Their modeling required simplifying their fault source into four segments with variable lengths that ranged from 3 to $41 \mathrm{~km}$ and used the relations of Slemmons and Polo (1992) to obtain a dip-slip of $4 \mathrm{~m}$. Their modeling results did not yield the observed leading depression wave, but rather predicted a minimal leading elevated wave followed by a prominent depression with a maximum run-up at northwestern Puerto Rico (Punta Agujereada; see Fig. 1 for location) of up to $9 \mathrm{~m}$. Although their results do not match completely the observed run-up and polarity, their computed arrival time were was in good overall agreement with the observed arrival time.

\section{Geologic evidence}

\subsection{Multibeam bathymetry}

Multibeam bathymetry data of the Mona Passage shows that the Mona Rift shallows to the south and ends at latitude $18.4^{\circ} \mathrm{N}$ along the Desecheo Ridge. The east-west trending Desecheo Ridge connects Desecheo Island with the western tip of Puerto Rico, and separates the Mona Rift in the north from the Mayagüez Basin to the south (Chaytor and ten Brink, in prep.). It is asymmetric with a steep south-facing scarp and a northward-tilted block surface with an average dip of $10^{\circ}$. Seismic profiles (Fig. 2) and available seafloor samples (Perfit et al., 1980 ) indicate that the tilted surface is a continuous layer of carbonate rocks, except for the ridge crest and Desecheo Island where volcanic/ volcano-clastic rocks are exposed.

A polygonal escarpment centered at $18.49^{\circ} \mathrm{N}, 67.35^{\circ} \mathrm{W}$ shows very steep faces $\left(29^{\circ}-45^{\circ}\right)$ which may indicate recent slumping (Fig. 1). The landslide excavation area is $9 \mathrm{~km}$ wide in its widest area (E-W) and is on average $9 \mathrm{~km}$ long. The shallowest depth of the headwall scarp and the northern terminus of the scarps are at a depth of 1200 and $3000 \mathrm{~m}$, respectively. Its total area is $76 \mathrm{~km}^{2}$. While the headwall scarp can be easily identified, the slide toe is not as clear and was estimated to be at a depth of $4200 \mathrm{~m}$. The excavated mass likely started moving northward but then continued to travel northwestward into the open area of the Mona Rift. If the excavated material reached a depth of $4200 \mathrm{~m}$, then the runout length was $28 \mathrm{~km}$ long.

Following the method outlined in ten Brink et al. (2006), Chaytor and ten Brink, (in prep.) obtained an excavation volume of $10 \mathrm{~km}^{3}$ by subtracting the bathymetry from an extrapolated smooth surface connecting the scarps. Dividing the volume by the area yields an average slide thickness of $140 \mathrm{~m}$, which is in very good agreement with the $150 \mathrm{~m}$ of vertical offset seen on the seismic profiles (Fig. 2b).

\subsection{Seismic profiles}

Seismic reflection lines 56 and 61 (Fig. 2a and b) show dip and strike cross sections of the landslide and indicate that the uppermost layers of the tilted carbonate platform have been dislodged, perhaps along a weaker interface in the carbonate layers that resulted in the material being deposited downslope.

On the other hand, seismic line 49 and the western portion of line 61 show no apparent recent activity on the faults proposed by Mercado and McCann (1998) as can be evidenced by the absence of surface rupture and the lack of an offset in the upper layer reflectors (Fig. 2).

\subsection{Rupture of submarine telegraph cables}

The timing of the submarine landslide is constrained by breaks of two underwater telegraph cables. The first cable, laid in 1870 connected San Juan, Puerto Rico with Kingston, Jamaica. The second cable was laid in 1891 and connected Puerto Plata in northern Dominican Republic with Charlotte Amalie, St. Thomas (Burns, 2007).

Reid and Taber (1919) visited Puerto Rico one month after the earthquake to conduct a field survey. They included in their report comments and observations from the cable ships in charge of cable recovery and repair. According to the report, the ruptures of the cables occurred between latitudes $18.42^{\circ}$ and $18.58^{\circ}$ north and longitudes $67.25^{\circ}$ and $67.5^{\circ}$ west. Fig. 1 shows that our identified landslide with fresh scarps is located within this area, represented with a dotted line bounding box. A third cable between San Juan and Mayagüez was located closer to shore and was not damaged (Reid and Taber, 1919). The observations made at the time of cable recovery and repair suggested that the break was caused by a landslide because it was stated that the cables were found buried for several kilometers under the sedimentary debris at depths ranging from 900 to $2000 \mathrm{~m}$ (Reid and Taber, 1919). According to Reid and Taber (1919) the French telegraph company La Societé Franaise des Télégraphes Sous-Marine reported that the Puerto Plata-St. Thomas cable suffered deformation, crushing and heavy scraping on its outer sheath, which suggests that the cable was subjected to debris impact, rather than a single fault rupture. It is therefore likely that the landslide shown in Fig. 1 was the direct result of the October 11, 1918 earthquake and it occurred during or immediately after it.

\section{Evidence for the earthquake and the tsunami}

\subsection{The earthquake}

The qualitative analysis of Reid and Taber, based solely on intensity distributions, led them to place the epicenter at $18.5^{\circ} \mathrm{N}, 67.3^{\circ} \mathrm{W}$ (Fig. 1 ). This location is approximately $15 \mathrm{~km}$ west of Punta Borinquen, Aguadilla, and close to the location of the identified fresh submarine landslide reported here. The seismic waves were felt as far as $450 \mathrm{~km}$ east of the origin at St. Martin, and as far west as Haiti. The estimated shaking in a Rossi-Forel scale, which was adjusted for local conditions, ranged from IX in the near-field (Aguadilla) to V in the Virgin Islands and Santo Domingo, Dominican Republic and III in St. Martin and Haiti (Reid and Taber, 1919). The majority of the casualties occurred in western Puerto Rico due to building collapse and drowning from the tsunami. According to the survey, two earthquakes were felt with a time difference of about 2 min. The first one lasted approximately $2 \mathrm{~min}$ and was described by initial vertical motion followed by horizontal northeast-southwest movements, which were responsible for most of the structural damage. The second event had a duration of $\sim 30 \mathrm{~s}$. Whether the seismic waves were the result of two separate earthquakes is questionable given that a single event with slow rupture velocities and a variable slip distribution due to an asperity could have yielded a similar result. 

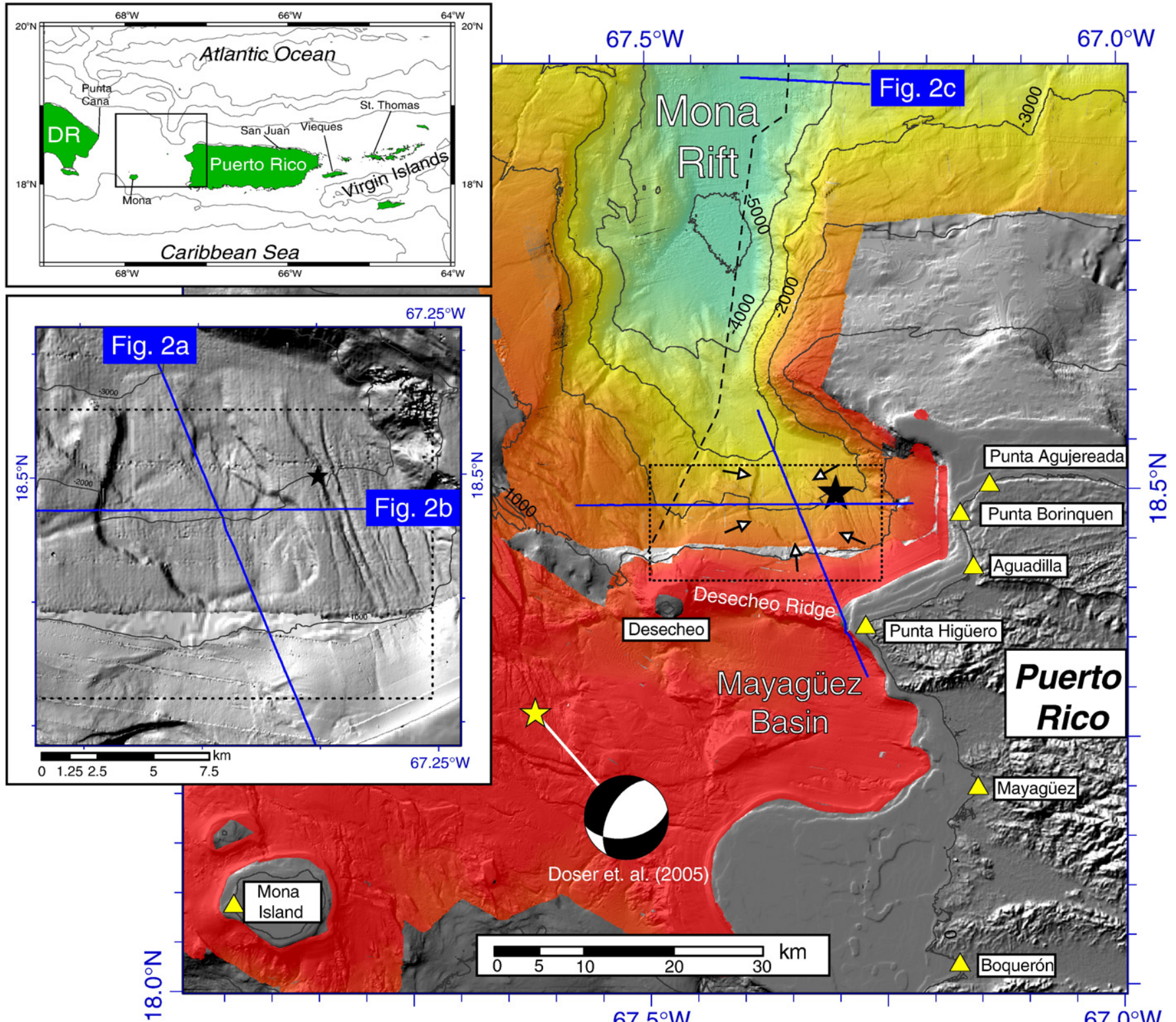

\section{Puerto}

Doser et. al. (2005)

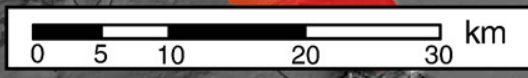

$67.5^{\circ} \mathrm{W}$

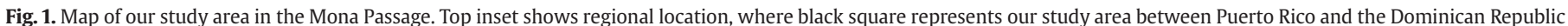

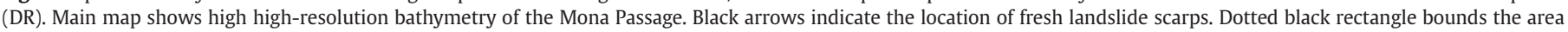

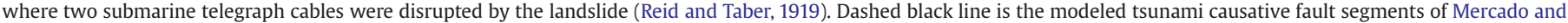

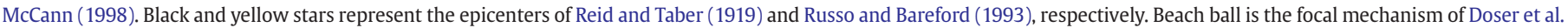

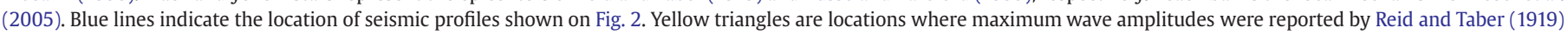
(see Table 1). Center inset - A detail of the shaded relief bathymetry illuminated from the NW which clearly shows the steep walls of the landslide.

Reid and Taber (1919) also reported on the number of aftershocks felt and recorded by seismic station VQS in the island of Vieques (see top inset in Fig. 1 for location). A total of 112 aftershocks were reported until March 1919 with the strongest occurring on October 24 and November 12. Interestingly, the aftershock during the night of October 24 once again broke submarine cables in the same location as the mainshock, but only the former was capable of producing a slight disturbance at the tide gauge at Galveston, Texas.

Doser et al. (2005) performed waveform inversion to obtain a focal mechanism that suggests rupture along a west dipping normal fault oriented NNE-SSW with a slight dextral strike-slip component $\left(\varphi=207^{\circ}, \delta=54^{\circ}, \lambda=-127^{\circ}\right)$ at $20 \pm 7 \mathrm{~km}$ depth. Although Reid and Taber (1919) noted that the earthquake was recorded on more than fifty stations all around the globe, Doser et al. (2005) based their computations on data recorded at only three stations (La Paz, Bolivia; Uccle, Belgium; Uppsala, Sweden). Despite that limitation they were able to obtain a moment magnitude $\left(M_{\mathrm{W}}\right)$ of 7.2, which corresponds to a seismic moment $\left(M_{0}\right)$ of $64 \pm 7 \times 1025 \mathrm{dyn} \mathrm{cm}$ and a slip of $\sim 3 \mathrm{~m}$. High uncertainty in the focal mechanism and a complex source-time function for the main event (Doser et al., 2005) may be indicative of a very slow earthquake rupturing a fault plane with a large asperity. Russo and Bareford (1993) and Russo (pers. comm., 2008) performed re-location of historical earthquakes in the Caribbean and placed the October 11, 1918 epicenter at $18.28^{\circ} \mathrm{N}, 67.62^{\circ} \mathrm{W}$ (yellow star in Fig. 1). Doser et al. (2005) adopted this epicenter for their study. However, multibeam bathymetry gridded at a resolution of $30 \mathrm{~m}$ does not show evidence of a recent surface rupture in the epicenter region.

Even if the earthquake's coseismic displacement occurred on a blind fault at that location, it would still be an improbable source for the tsunami because it would have yielded different results (i.e. arrival time, polarity, run-up distribution, etc.). It should also be noted that we found a georeference error in Doser et al. (2005) figures, hence 


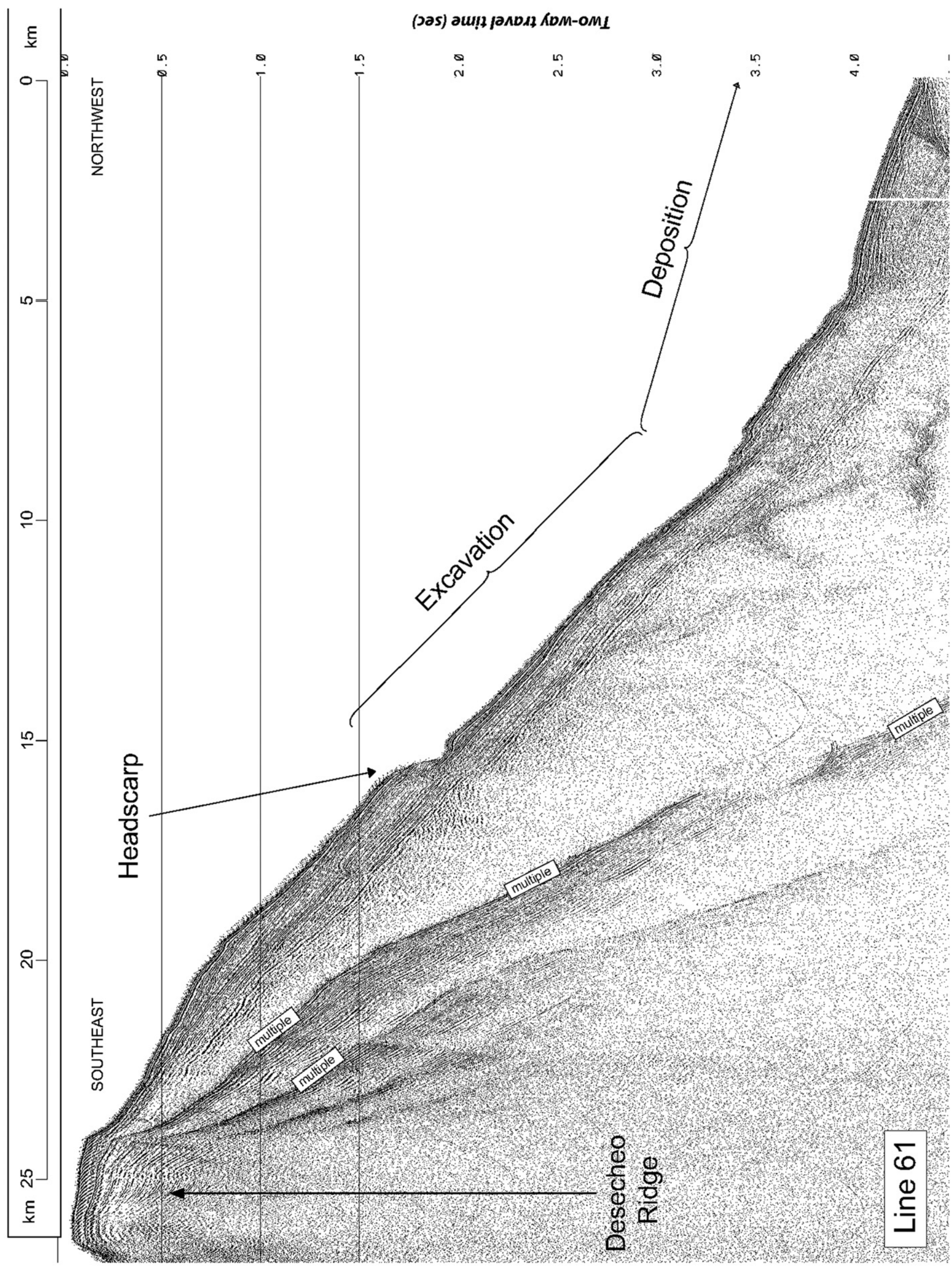




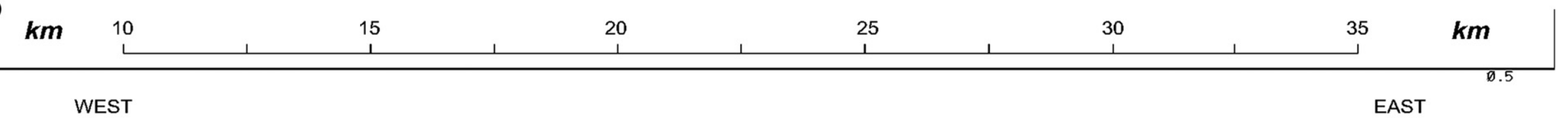

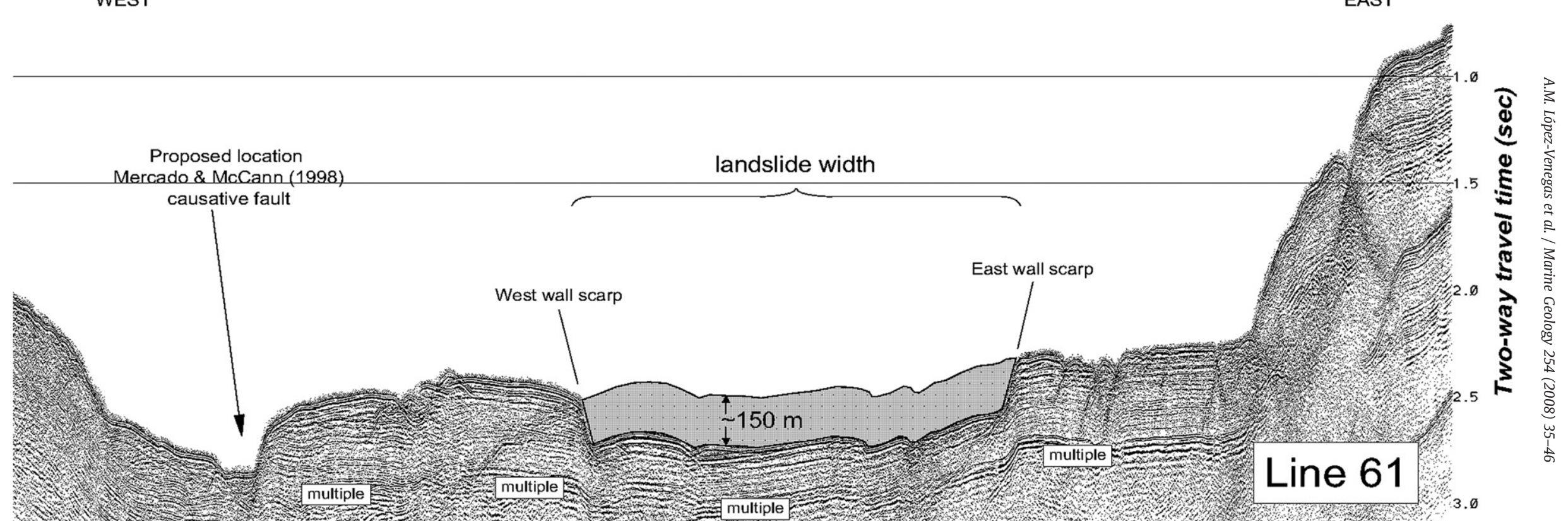

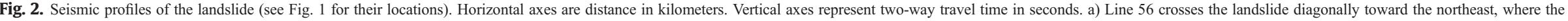

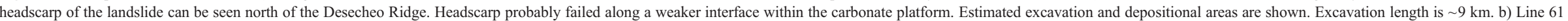

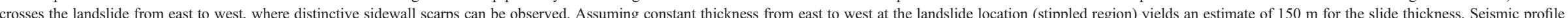

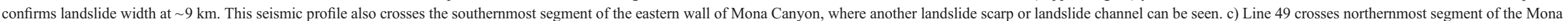
Canyon fault, where recent activity seem to be the separation of landslide blocks from the uppermost carbonate layer. 


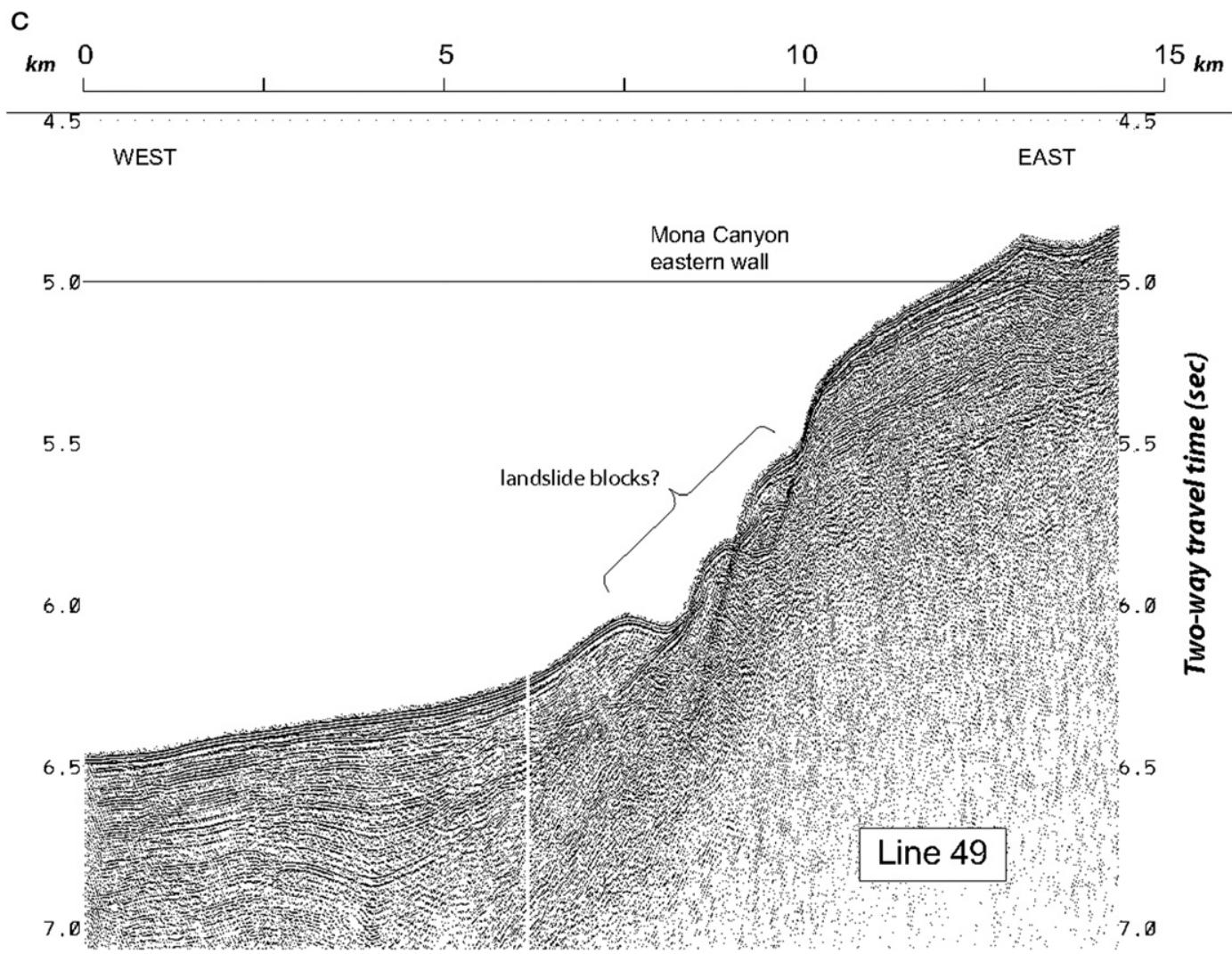

Fig. 2 (continued).

their epicenters are plotted incorrectly on their maps. This may have led them to agree with the suggestions of Mercado and McCann (1998) and to conclude the earthquake occurred along two or more normal fault segments of the Mona Rift eastern wall. In reality, the epicenter of Russo and Bareford (1993) lies more than $40 \mathrm{~km}$ southwest of the Mona Canyon fault (Fig. 1).

Regardless of which epicenter is used, it is widely accepted in the seismological community that earthquake data from early 20th century have rather large uncertainties associated with time keeping and instrumentation. As a result, the epicenter could be anywhere in the Mona Passage. In view of the discrepancies between suggested epicenters, we simply acknowledge that the seismic source in the area is indirectly related to the tsunami. If the earthquake occurred along the eastern wall of Mona Rift, as suggested by Mercado and McCann (1998), then it was unable to rupture the surface, and thus unable to generate the tsunami.

\subsection{Tsunami observations}

The survey of Reid and Taber (1919) is the most comprehensive report describing the damage caused by the tsunami and the extent of the waves at various locations. Table 1 summarizes run-up, inundation and wave arrival times along the western coast of Puerto Rico according to witnesses interviewed during that survey. Wave heights were higher in northwest Puerto Rico and lower values south of Punta Higüero. Based on this southward decrease in amplitude and their seismic intensity analysis, Reid and Taber (1919) justified their epicenter location close to the northwestern coast of Puerto Rico. It is unfortunate that no records exist (to our knowledge) of the earthquake and tsunami in eastern Dominican Republic. Data from the other side of the Mona Passage is however, not critical for this study but nonetheless would benefit by providing a more robust constrain on the source.
According to Reid and Taber's survey, all reported locations in western Puerto Rico observed a tsunami leading depression wave. In Punta Borinquen (see Fig. 1 for location), the lighthouse keeper observed the sea receding shortly after he felt the mainshock, whereas the lighthouse keeper at Punta Higüero related that the sea returned $\sim 2$ min after it receded shortly after the earthquake. In Boquerón a maximum depression of the sea was estimated at $1.5 \mathrm{~m}$ by an eyewitness account describing how a small boat anchored $50 \mathrm{~m}$ from the shore rested on the sea floor for about $5 \mathrm{~min}$.

Wave arrival accounts range from immediate at northwestern Puerto Rico to an hour after the earthquake in the southwest.

Table 1

Observed and computed values for western Puerto Rico: run-up and inundation values (where available) and arrival times of first depression wave taken from Reid and Taber (1919)

\begin{tabular}{|c|c|c|c|c|c|}
\hline \multirow[t]{3}{*}{ Location } & \multicolumn{2}{|c|}{ Observed } & \multicolumn{3}{|c|}{ Computed } \\
\hline & \multirow{2}{*}{$\frac{\text { Run-up }}{(\mathrm{m})}$} & \multirow{2}{*}{$\begin{array}{l}\text { Arrival time } \\
\text { (min) }\end{array}$} & \multicolumn{2}{|c|}{$\begin{array}{l}\text { Max wave height } \\
(\mathrm{m})\end{array}$} & \multirow{2}{*}{$\begin{array}{l}\text { Arrival time } \\
(\mathrm{min})\end{array}$} \\
\hline & & & $C_{\mathrm{f}}=0.01$ & $C_{\mathrm{f}}=0.04$ & \\
\hline Punta Agujereada & $5.5-6$ & - & 10.67 & 8.22 & 7 \\
\hline Punta Borinquen & 4.6 & - & 8.97 & 8.27 & 5 \\
\hline Aguadilla & $>4.0$ & $5-6$ & 12.83 & 13.69 & 7 \\
\hline Punta Higüero & 5.5 & - & 6.23 & 5.89 & 5 \\
\hline Mayagüez & $1.1-1.5$ & $25-30$ & 2.70 & 2.63 & 18 \\
\hline Mona Island & $>4.0$ & - & 3.42 & 2.27 & 18 \\
\hline Boquerón & 1.1 & 45 & 1.65 & 0.74 & 44 \\
\hline Volume $\left(\mathrm{km}^{3}\right)$ & $10^{a}$ & & 8.85 & & \\
\hline Slide thickness (m) & $150^{\mathrm{b}}$ & & 155 & & \\
\hline
\end{tabular}

Computed values were obtained using the best-fit slide parameters discussed in the text. Computed arrival times are in agreement with available observations. $C_{\mathrm{f}}=$ Bottom friction coefficient .

a Estimated average volume (Chaytor and ten Brink, in prep.).

b Average value estimated using seismic reflection line 61 (see Fig. 2). 
Witnesses from the town of Aguadilla recount the sea receding 4 to 7 min after the earthquake, whereas in Mayagüez there is an account of a witness driving from Rincón immediately after the earthquake occurred and arriving at Mayagüez 25-30 min after, just as the first sea withdrawal occurred in that city. Reid and Taber (1919) computed $23 \mathrm{~min}$ for the leading wave to arrive at this location, whereas at Boquerón they estimated 45 min. However, anecdotal accounts in their report place the first arrival of the tsunami at Boquerón $1 \mathrm{~h}$ after the earthquake with "water going out gradually during a period of twenty minutes".

The tsunami also appears to have affected the eastern coast of the Dominican Republic, but run-up and inundation information was not found. Anonymous accounts in local newspapers describe the drowning of one woman in Punta Cana (see location in top inset of Fig. 1) as a result of the tsunami waves coming ashore, and fluctuations of approximately 1 or $2 \mathrm{ft}$ in the Ozama river in Santo Domingo (McCann pers. comm., June, 2008).

It is unclear whether some reports of minor sea level fluctuations in St. Thomas, Santo Domingo and as far as Atlantic City, New Jersey are related to this tsunami. Unfortunately, tide gauges in Puerto Rico and the Dominican Republic were not present at the time of the tsunami, and those who were; one in New York harbor and another in Key West did not record any perturbations. The fact that these reports are questionable reinforces the concept of a landslide source given that tsunamis from earthquake displacements tend to be more noticeable in the far-field, whereas those generated by landslide sources do not produce the same effect in the far-field but are catastrophic in the near-field (Okal and Synolakis, 2004).

\section{Tsunami modeling}

In light of the evidence for a large slope failure during the 1918 earthquake, we next model the landslide as the source of the tsunami and compare the simulation results with the observations reported by Reid and Taber (1919).

\subsection{COULWAVE modeling package}

We employed the Cornell University Long and Intermediate Wave Modeling Package, commonly known as COULWAVE (Lynett and Liu, 2002) to perform tsunami simulations. The package applies both linear and non-linear effects at the source location, shallow areas, and the coast making it a robust and ideal method for our scenario. In addition, this package allowed us to vary the bottom friction coefficient and slide duration. A thorough description of the model and the underlying equations is given by Lynett and Liu (2002). Here we discuss only the particular details of the model that pertain to the setup for our tsunami modeling simulations.

We specified the use of the fully non-linear, dispersive set of governing equations for instances when the wave amplitudes became comparable to water depths, and non-dispersive shallow water wave equations for instances when the ratio between water depth and wavelength was very small. To avoid having unwanted reflections at the grid boundaries we used a non-reflective boundary condition. Each simulation had a duration of $100 \mathrm{~min}$ in order to compute an extended wave time history at each site of interest. We used either 5 or 20 grid points/wavelength which resulted in $1600 \mathrm{~m}$ and $400 \mathrm{~m}$ of grid resolution, respectively. The coarse resolution provided fast computations that we employed in estimating the slide duration $\left(t_{\mathrm{d}}\right)$ and bottom friction coefficient $\left(C_{\mathrm{f}}\right)$, while the highest resolution was used for the final simulations. To ensure simulation stability we used a value of 0.1 for the Courant number.

A combined bathymetry and topography grid with a resolution of 1 " for the Puerto Rico area was obtained from NOAA and was downsampled to $200 \mathrm{~m}$ resolution and projected in UTM coordinates. The western limit of the NOAA grid was close $(7 \mathrm{~km})$ to the western coast of Mona Island.
Having one of the compared sites (southwest Mona Island) close to the grid boundaries would have resulted in unwanted edge effects. Hence, we added an additional $41 \mathrm{~km}$ to the western side of the grid with $200 \mathrm{~m}$ resolution bathymetry available from the USGS. The area of the grid extends roughly from $68.4 \mathrm{~W}$ to $67.2 \mathrm{~W}$ and from $17.7 \mathrm{~N}$ to $18.75 \mathrm{~N}$. COULWAVE has been coded to produce slides in the direction of the abscissa. According to spatial analysis, the slope orientation in the area of the landslide is $350 \pm 5$. Therefore, we rotated the grid $10^{\circ}$ clockwise in order to feature the landslide parallel to the ordinate. The resulting grid had dimensions of $134 \mathrm{~km}$ wide (NNW-SSE) by $157 \mathrm{~km}$ long (WSW-ENE).

Because the simulation area was small relative to the simulation time, the propagated waves reached the edges of the grid before completion of the simulation, thus potentially introducing boundary effects. To prevent these unwanted effects, a sponge layer $12.5 \mathrm{~km}$ wide was placed at the edges of the grid to absorb the wave energy.

\subsection{Parameters of the submarine landslide}

We performed our simulations using the 2D wave generation by a rotational submarine landslide source. We used in our simulations 1200 and $4200 \mathrm{~m}$ for the top and bottom of the slide, respectively. The midpoint of the slide was placed at $3000 \mathrm{~m}$, which corresponds to the depth in the bathymetry where an inflection occurs between the end of the excavation area and the beginning of the depositional area.

We think that the excavated material found its way to the deepest portions of the Mona Rift. This would imply that the landslide propagated northward with the initial failure, then encountered the eastern wall of the Mona Rift, which forced the flow downslope toward the northwest, and finally north where the remaining material was deposited in the Mona Rift. Our modeling, on the other hand, required both excavation and deposition areas to be on a straight line, hence we had to shift the location of the landslide westward by $8 \mathrm{~km}$ in order to both avoid the eastern wall of the Mona Rift and obtain the deposition area on the Mona Rift (yellow rectangle in Fig. 3). As we will see in Section 6 , this offset only minimally affects the computed arrival times.

COULWAVE calculates rotational slides whose thickness varies along the excavation area. Hence, we searched for the rotation slide coefficient whose maximum thickness was slightly higher than the observed average thickness (see Section 3.1) and whose volume fits the calculated volume from the bathymetry.

In contrast to the a-priori knowledge of slide thickness, values for the bottom friction coefficient $\left(C_{\mathrm{f}}\right)$ and the duration of the slide $\left(t_{\mathrm{d}}\right)$ were unknown. We searched for the best values of these parameters by performing 130 simulations varying $C_{\mathrm{f}}$ and $t_{\mathrm{d}}$. The best values were found by minimizing the misfit between the reported run-up values of the seven sites in the survey of Reid and Taber (1919) and the calculated wave heights at the reported sites using the Chi square $\left(\chi^{2}\right)$ criterion:

$\chi^{2}=\sum_{i} \frac{\left(o_{i}-p_{i}\right)^{2}}{o_{i}}$

where $o_{i}$ are the observed data, $p_{i}$ is the data predicted by the model and $i$ are each of the seven reported sites. All of the 130 simulations in the first stage used a coarse grid resolution of $1600 \mathrm{~m}$ to reduce computation time. A range of slide durations from 75 to $400 \mathrm{~s}$, and $C_{\mathrm{f}}$ from $1 \times 10^{-3}$ to $6 \times 10^{-3}$ in $5 \times 10^{-4}$ increments, were tested. At this stage, we used a radius coefficient for a rotational slide which yielded a maximum slide thickness of $180 \mathrm{~m}$. Our test have shown that varying slide thickness did not change the best-fit parameters $C_{\mathrm{f}}$ and $t_{\mathrm{d}}$.Using this approach, the optimum value for slide duration; $t_{\mathrm{d}}$ is $325 \mathrm{~s}$. Although the fit improves with increasing $C_{\mathrm{f}}$, no minimum was found for the specified range. Hence, to find a best fit as a function of $C_{\mathrm{f}}$, we fixed the slide duration at $325 \mathrm{~s}$ and the thickness at $180 \mathrm{~m}$. Fig. 4 shows that the fit continues to improve to the maximum tested $C_{\mathrm{f}}$ of $6 \times 10^{-2}$, but the improvement is very small. An optimum value is found at $C_{\mathrm{f}}=4 \times 10^{-2}$, corresponding to $\chi^{2}=1$ (Fig. 4). 


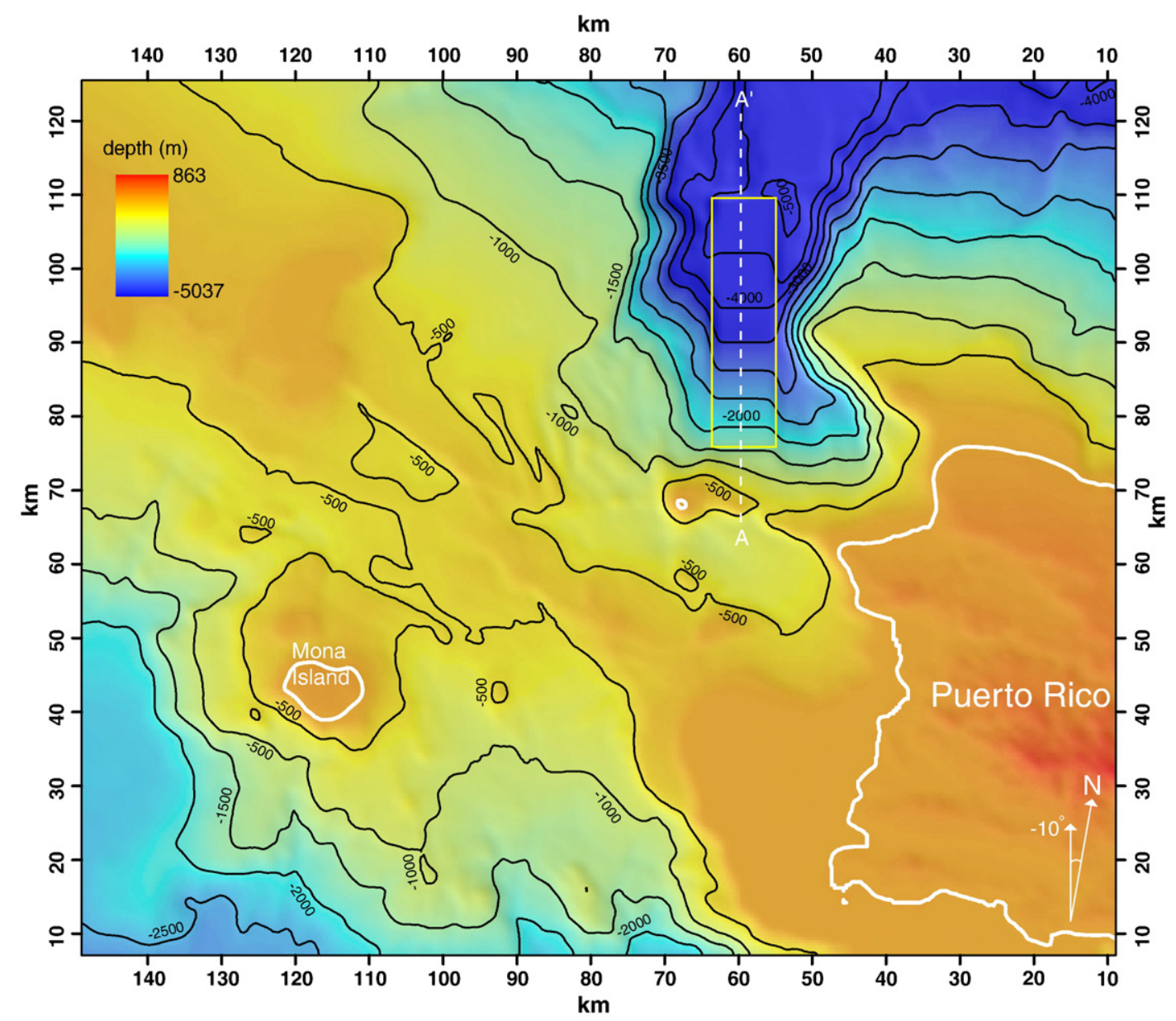

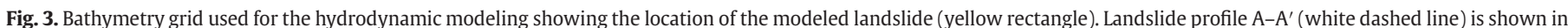

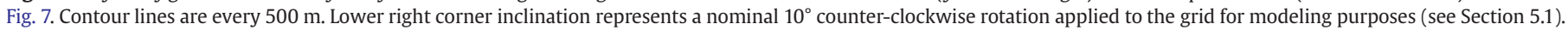

The second stage of the computations used the best-fit values with the higher resolution bathymetry ( $400 \mathrm{~m}$ ) to produce detailed results. Simulations were performed using a rotational slide with a maximum slide thickness of $155 \mathrm{~m}$. Although we performed these simulations with $C_{\mathrm{f}}=4 \times 10^{-2}$, corresponding to $\chi^{2}=1.4$, (Fig. 4) we consider this number to be excessively high, and thus ran additional simulations using a more conservative value of $1 \times 10^{-2}$. The values for the $\chi^{2}$ test for $C_{\mathrm{f}}=4 \times 10^{-2}$ and $1 \times 10^{-2}$ are shown as stars in Fig. 4 . Table 1 shows

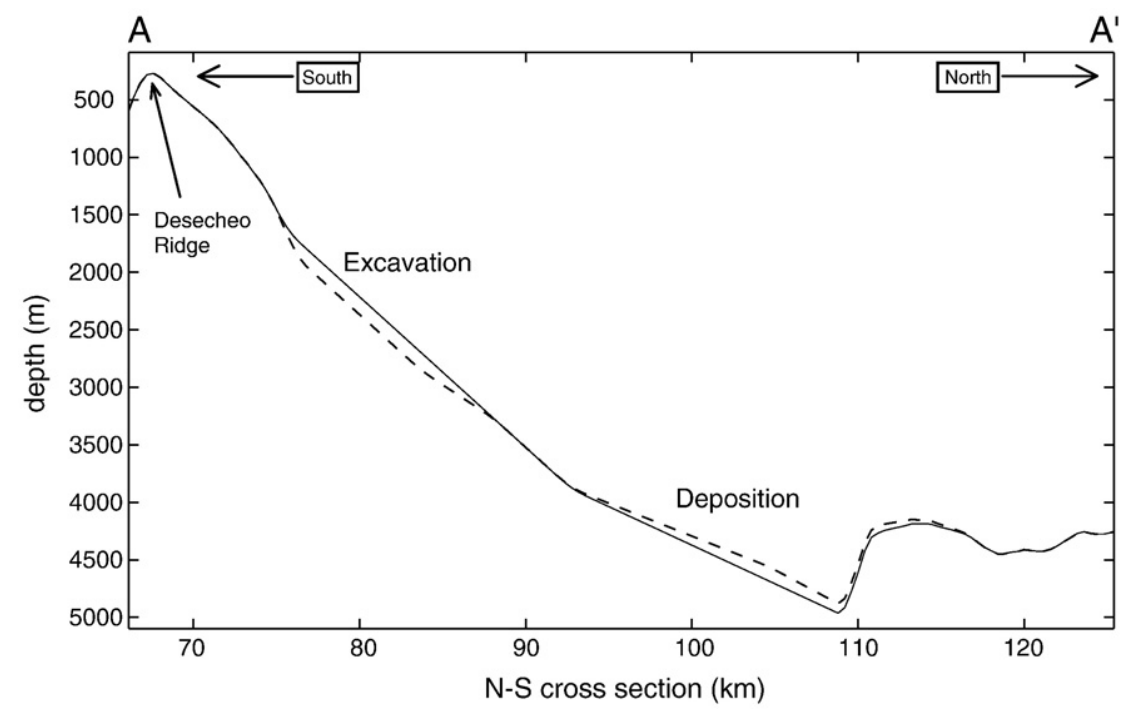

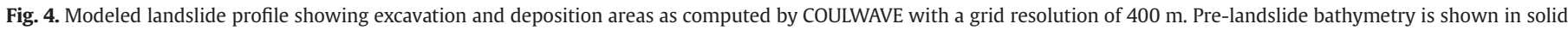

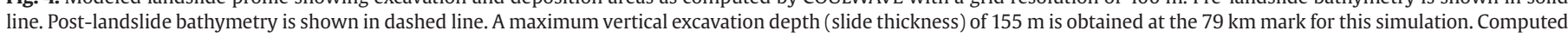
landslide excavation length is $13 \mathrm{~km}$ with the headscarp at $1400 \mathrm{~m}$ depth. 


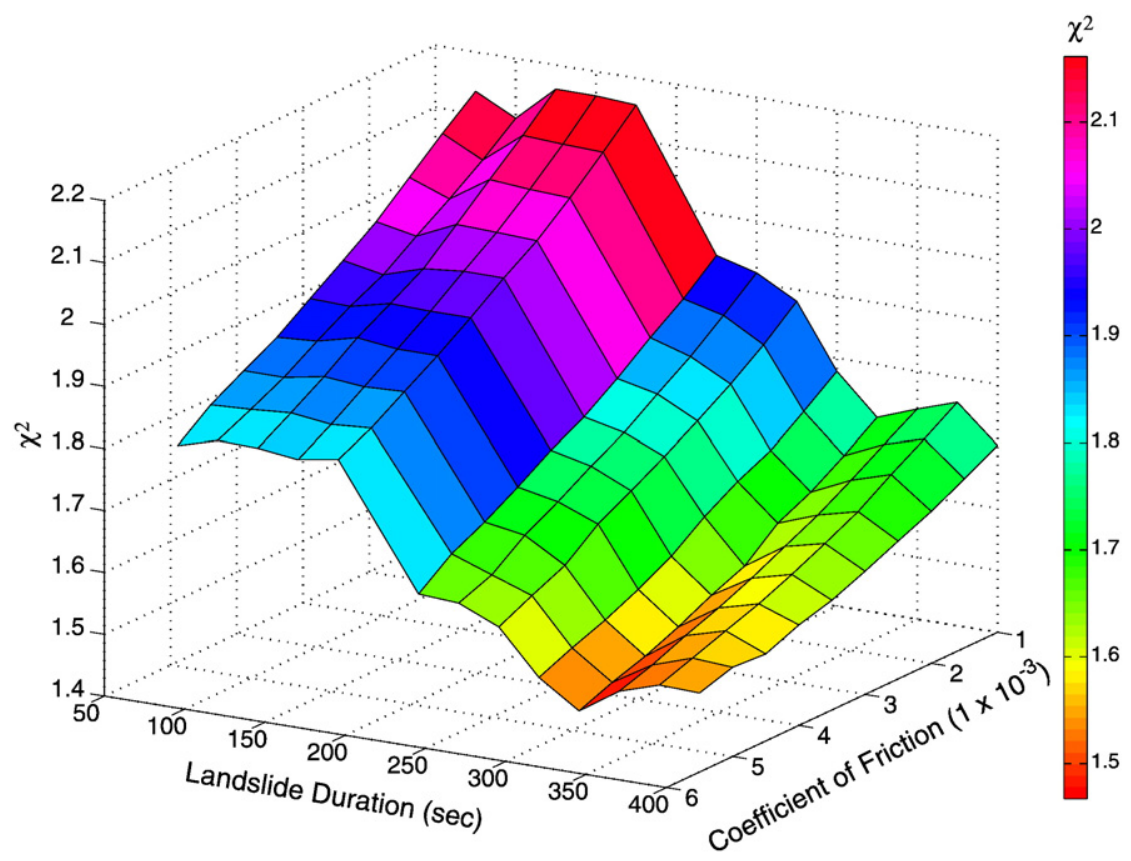

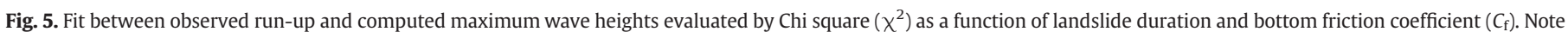

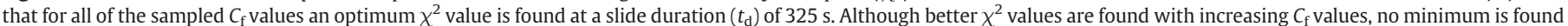
for the sampled range.

results from these simulation runs and compares them to observed values. Marigrams and maximum amplitudes shown in Figs. 5 and 6 were calculated using $C_{\mathrm{f}}=1 \times 10^{-2}$ and $t_{\mathrm{d}}=325 \mathrm{~s}$.

\section{Results and discussion}

The location and geometry of the identified landslide produce results which are in agreement with observations. The use of a rotational slide model yields excavation and depositional areas (Fig. 7) which produce a leading depression at all seven sites in western Puerto Rico (Fig. 5). The scenario of a normal fault, such as that proposed by Mercado and McCann (1998) has been shown to predict leading elevated waves. Another case is where an identified landslide along the western wall of the Mona Rift could have potentially caused the tsunami (Mondziel et al., 2006); not only would this also predict a leading elevated waves, but also wave arrival times would not agree with observations. Finally, a case scenario which would generate a leading depression wave would be a normal fault located on the western wall of the Mona Rift, however, due to its farther location, it would again lead to incorrect wave arrival times. Our results, showing that a leading depression wave arrives at specific sites of interests within the specified observed range (Fig. 5), suggests that our source location and motion is correct. An arrival time comparison (Table 1) shows the computed times are in good agreement with those sites where approximate timing is available. While arrival times at Boquerón and Aguadilla fit exceptionally well, Mayagüez is slightly

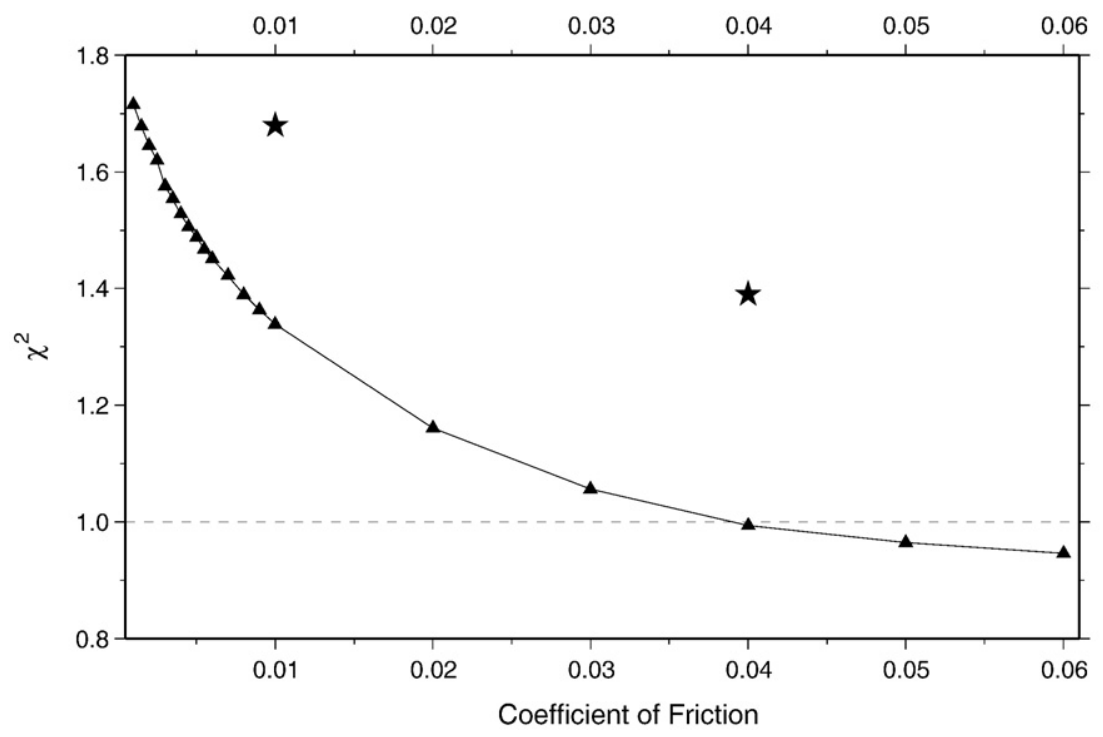

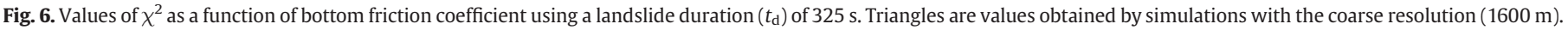

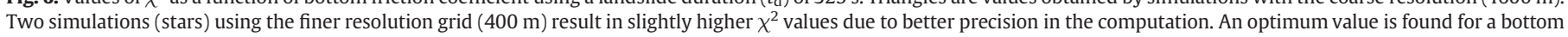
friction coefficient of $4 \times 10-2$. 

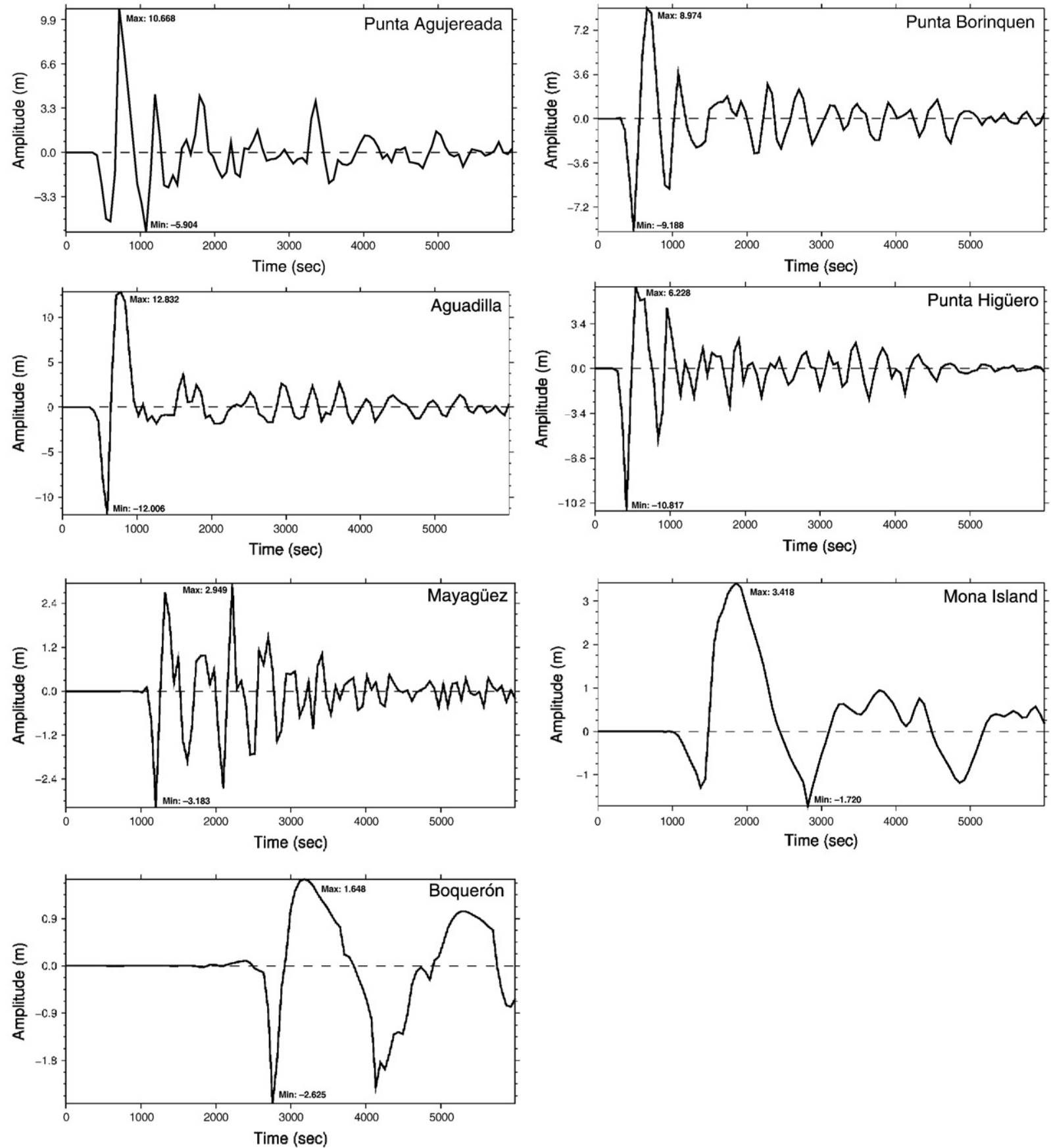

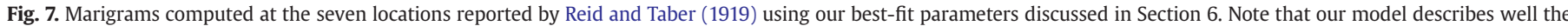
observed leading depression wave and arrival time at all seven sites.

faster than observed. Worth noting is the outstanding fit of our model to the time window between initial sea recession and the leading elevated wave at Punta Higüero and Boquerón (Fig. 5). Recalling witness accounts in Section 4.2, the lighthouse keeper at Punta Higüero estimated $\sim 2$ min and an observer in Boquerón described how a boat $50 \mathrm{~m}$ from the shore rested for $\sim 5 \mathrm{~min}$ on the sea floor. Although these values do not represent robust measurements, our model is able to describe well these time windows at 2.2 and $6.4 \mathrm{~min}$, respectively. The fact that our predicted arrival times are in such good agreement with observations suggests that the onset of the landslide failure occurred in conjunction with the initial seismic waves.

Maximum wave heights (Fig. 5) for the sites in northwestern Puerto Rico including Punta Borinquen, Punta Agujereada, and
Aguadilla are overestimated, whereas values for Punta Higüero, Mayagüez, Mona Island, and Boquerón are in good agreement with observations. However, the model is able to describe well the overall distribution pattern, in which the highest values are observed in northwestern Puerto Rico. A combination of marigram location and grid resolution may explain why northwestern sites are overestimated (Fig. 6) and will require the use of higher resolution grids to estimate precisely run-up values on land.

Our computations varying the bottom friction coefficient yielded a best fit $\left(\chi^{2} \sim 1\right)$ at $C_{\mathrm{f}}=4 \times 10^{-2}$ (Fig. 4). However, since the friction coefficient is related to water depth and higher values are associated with run-up on land, we opted to use a conservative value of $1 \times 10^{-2}$, as the best option for our simulations. Modeling the 1992 Nicaragua 
tsunami, Satake (1995) used a $C_{\mathrm{f}}$ of $2.3 \times 10^{-3}$ and $1 \times 10^{-2}$ for depths of 50 and $0.6 \mathrm{~m}$, respectively, and found those numbers to be in good agreement with observational values of tidal flow and tsunami runup. As can be seen in Table 1 , amplitudes obtained using $C_{\mathrm{f}}=4 \times 10^{-2}$ are only slightly smaller overall than those found using $1 \times 10^{-2}$.

The best-fit source duration of the landslide was $325 \mathrm{~s}$ (Fig. 8). This duration translates to an average slide velocity of $27 \mathrm{~m} / \mathrm{s}$ if the whole $9 \mathrm{~km}$ of the excavation length is used. Such a velocity indicates that the mass of the landslide propagated at slower velocities, much like the 25-30 m/s slide velocity range proposed by Bondevik et al. (2001) for the Storegga, Norway slide. The lack of a debris field containing large blocks of carbonate at the toe of the scarp supports this assertion.

The previous mechanism suggested by Mercado and McCann (1998) predicts acceptable arrival times mainly due to rupture on the southernmost portion of their fault. However, the northern segment on their proposed fault, north to latitude $19^{\circ} \mathrm{N}$ would have induced considerable wave amplitudes farther east along the northern Puerto Rico coast. Although wave amplitudes for the northern coast were not computed by these authors, Reid and Taber's survey does not mention extraordinary wave amplitudes along the northern coast.

They do mention a "large enough wave" observed at Isabela and Arecibo, and a fluctuation of $\sim 1 \mathrm{~m}$ at the estuary of the Río Grande de Lóıza, but no apparent disturbance in San Juan Bay. Performing a simulation using the entire Puerto Rico grid is essential to confirm whether our source is in agreement with these observations, however, at this point our current computing power has limited the size of our model grid. The best arguments for a landslide being the 1918 tsunami source are the geologic and historic evidence. Our simulation results agree with the observed landslide location, thickness and area. The total calculated volume of $8.8 \mathrm{~km}^{3}$ is slightly less than the volume of $10 \mathrm{~km}^{3}$ obtained through spatial analysis of the bathymetry, perhaps because only a percentage of this volume contributed to the tsunami genesis.

We postulate that the entire excavation area of the failed in a single event. The fact that the two submarine telegraph cables ruptured simultaneously in the area of the landslide as a consequence of being abraded and buried by debris is a strong evidence that a massive landslide occurred and supports the idea the landslide occurred due to the seismic energy released by the earthquake.

\section{Conclusions}

The October 11,1918 Mona Passage earthquake triggered a tsunami that affected the western coast of Puerto Rico. The cause of the tsunami was previously suggested to be due seafloor displacement by a normal fault on the eastern wall of the Mona Rift (Mercado and McCann, 1998). We have identified a submarine landslide with steep headwall and sidewalls scarps $15 \mathrm{~km}$ off the northwestern coast of Puerto Rico using newly available multibeam bathymetry and multichannel seismic reflection profiles. Based on these new data we postulate that the landslide, which was induced by the earthquake, was responsible for the generation of the tsunami. Supporting this idea is the documented rupture of submarine telegraph cables by landslides in the area of our mapped landslide during the earthquake (Reid and Taber, 1919). The landslide, which is well marked by fresh and steep scarps, is $9 \mathrm{~km}$ wide by $9 \mathrm{~km}$ in length in the excavation area, and it has an average thickness of $140-150 \mathrm{~m}$. We modeled the tsunami generated by a landslide in this location and with these dimensions using the weakly non-linear "extended" equations implemented in the hydrodynamic modeling

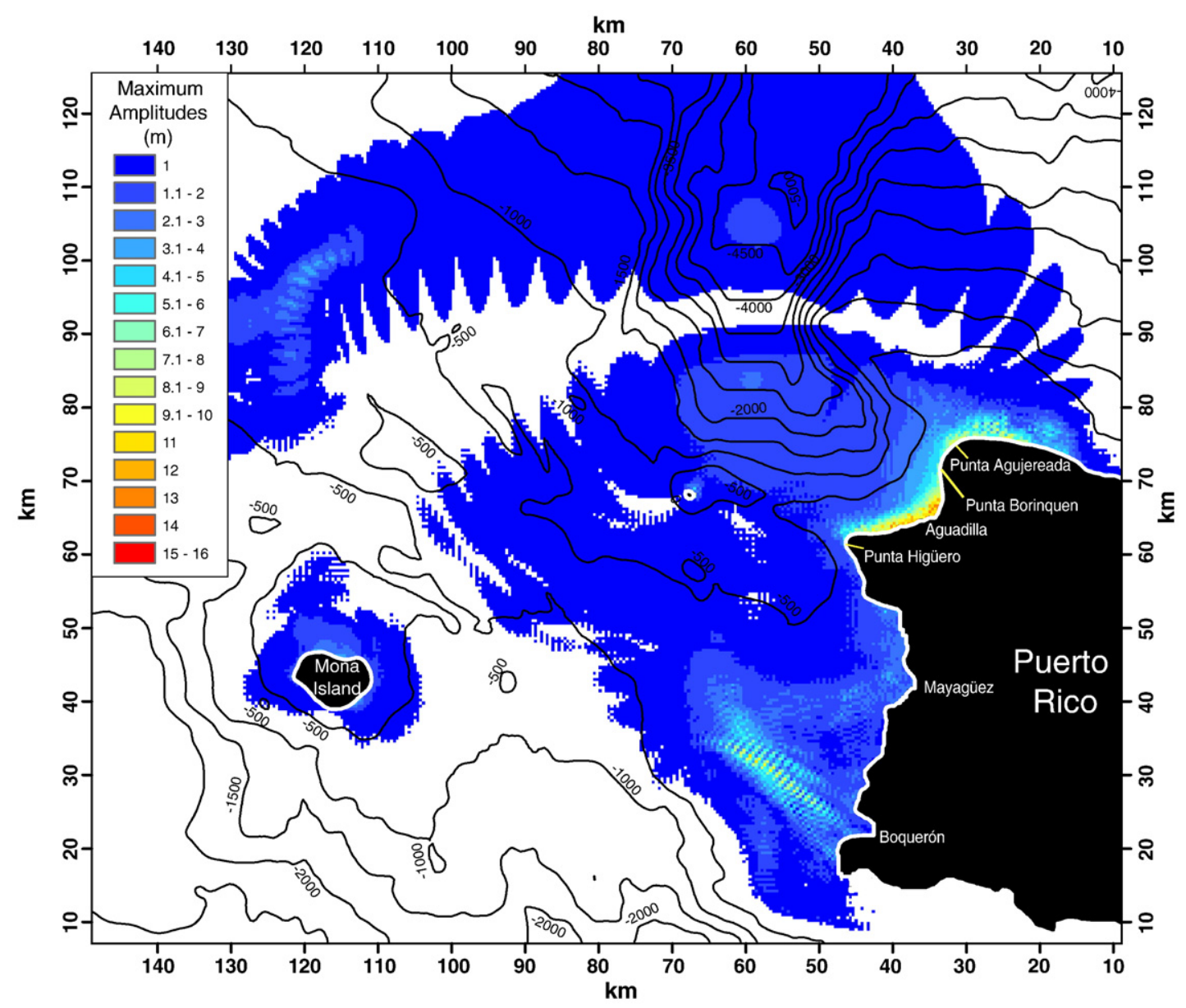

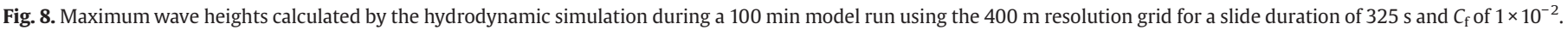


package COULWAVE. The models show: 1) Waves generated at the location of the identified slide propagate within the range of observed arrival times; 2) The landslide geometry produces a leading depression wave at all sites where it was observed; 3 ) The landslide most probably had a source duration of $325 \mathrm{~s}$, which translates to an average slide velocity of $27 \mathrm{~m} / \mathrm{s}$ over the $9 \mathrm{~km}$ long excavation area; 4) The best-fit bottom friction coefficient yields $4 \times 10^{-2}$ but the predicted wave amplitudes are not much different for a more conservative value of $1 \times 10^{-2}$; and 5) Using a maximum slide thickness of $155 \mathrm{~m}$ yields a total volume displaced of $8.8 \mathrm{~km}^{3}$ and maximum wave amplitudes in agreement with the observed data.

This study highlights the need for high-resolution bathymetry and post-tsunami observations to accurately determine the mechanism of the tsunami and produce results in agreement with both geologic evidence and observations. Past tsunamis where the source is poorly understood, would benefit from the use of accurate bathymetry and high high-resolution seismic profiles coupled with a realistic model for landslide generated tsunamis. An example is the Hispaniola August 4, 1946 tsunami, where the paucity of geologic data have has prevented the cause of the tsunami to be fully understood (López, 2006; López and Okal, 2007).

\section{Acknowledgments}

Technical assistance by Jason Chaytor, Claudia Flores and Patrick Lynett is gratefully appreciated. We would like to thank Jason Chaytor, Holly Ryan and two anonymous reviewers for their comments and useful suggestions.

\section{References}

Bondevik, S., Lovholt, F., Harbitz, C.B., Mangerud, J., Dawson, A., 2001. The Storegga slide tsunami: comparing field observations with numerical simulations. Mar. Pet. Geol. 22, 195-208.

Burns, B., , 2007. http://www.atlantic-cable.com.
Doser, D.I., Rodríguez, C.M., Flores, C., 2005. Historical earthquakes of the Puerto RicoVirgin Islands region (1915-1963). In: Mann, P. (Ed.), Active tectonics and seismic hazards of Puerto Rico, the Virgin Islands, and offshore areas. Special Paper vol. 385. The Geological Society of America, pp. 103-114.

Gutenberg, B., Richter, C.F., 1954. Seismicity of the Earth. Princeton Univ. Press.

Jansma, P.E., Mattioli, G.M., López, A.M., DeMets, C.D., Dixon, T.H., Mann, P., Calais, E., 2000. Neotectonics of Puerto Rico and the Virgin Islands, northeastern Caribbean, from GPS geodesy. Tectonics 19 (6), 1021-1037.

López, A.M., August 2006. Tectonic Studies of the Caribbean: Pure GPS Euler Vectors to Test for Rigidity and for the Existence of a Northern Lesser Antilles Forearc Block Constraints for Tsunami Risk from Reassessment of the April 1, 1946 AlaskaAleutians and August 4, 1946 Hispaniola Events. Ph.D. thesis, Northwestern University.

López, A.M., Okal, E.A., 2007. Assessment of energy release and seismic moment of the August 4, 1946 Hispaniola earthquake. Annual Meeting. Seismological Society of America, Waikoloa, Hawai'i. p. abstract.

Lynett, P., Liu, P.L., 2002. A numerical study of submarine landslide generated waves and runup. Proc. R. Soc. Lond., A 458, 2885-2910.

Mann, P., Burke, K., 1984. Neotectonics of the Caribbean. Rev. Geophys. 22, 309-362.

Mercado, A., McCann, W., 1998. Numerical simulation of the 1918 Puerto Rico tsunami. Nat. Hazards 18, 57-76.

Mondziel, S.A. Grindlay, N.R., Mann, P. Escalona, A, 2006. Multi-channel seismic images of Neogene rifting in the northern Mona Passage between Puerto Rico and Hispaniola. Eos Trans. AGU 87 (52) Fall Meeting Suppl., Abstract T43D-1679.

Okal, E.A., Synolakis, C.E., 2004. Source discriminants for near-field tsunamis. Geophys. J. Int. 158, 899-912.

Perfit, M.R., Heezen, B.C., Rawson, M., Donnelly, T.W., 1980. Chemistry, origin and tectonic significance of metamorphic rocks from the Puerto Rico Trench. Mar. Geol. 34, 125-156.

Reid, H.F., Taber, S., 1919. The Porto Rico earthquakes of October-November, 1918. Bull. Seismol. Soc. Am. 9 (4), 95-127.

Russo, R.M., Bareford, C., 1993. Historical seismicity of the Caribbean region, 1933-1963. Caribbean Conference on Volcanism, Seismicity and Earthquake Engineering. University of the West Indies, Trinidad.

Satake, K., 1995. Linear and nonlinear computations of the 1992 Nicaragua earthquake tsunami. PAGEOPH 144 (3/4), 455-470.

Slemmons, D.B., Polo, C.M., 1992. Evaluation of acting faulting and associated hazards In: Wallace, R.E. (Ed.), Active Tectonics. Studies in Geophysics. National Academy Press, Washington, D.C., pp. 45-62.

ten Brink, U., Dillon, W., Frankel, A., Rodrquez, R., Mueller, C., 1999. Seismic and Tsunami Hazard in Puerto Rico and the Virgin Islands. U.S. Geological Survey, pp. 99-353. Open-File Report.

ten Brink, U.S., Geist, E., Andrews, B.D., 2006. Size distribution of submarine landslides and its implication to tsunami hazard in Puerto Rico. Geophys. Res. Lett. 33, 4. 